\title{
Hiperplasia paratiroidea ectópica de doble localización, intratiroidea e intratorácica
}

\author{
Double ectopic parathyroid hyperplasia, intrathyroidal and intrathoracic
}

\author{
Francisco Avello Canisto ${ }^{1,2}$ \\ Servicio de Cirugia de Cabeza, Cuello y Máxilo-Facial del Hospital Nacional Dos de Mayo. \\ ${ }^{2}$ Departamento de Cirugia de la Universidad Nacional Mayor de San Marcos.
}

\begin{abstract}
Resumen
Se presenta el caso de una paciente sometida satisfactoriamente a hemitiroidectomía izquierda por diagnóstico de bocio nodular. El estudio anátomo-patológico de la pieza operatoria informó que el aumento de tamaño del lóbulo tiroideo izquierdo se debía a glándula paratiroides hiperplásica intratiroidea. Con este resultado se solicitó gammagrafía paratiroidea, en la que se encontró un área de captación en la región torácica derecha. Se concluyó que se trató de hiperplasia paratiroidea ectópica de doble localización, intratiroidea e intratorácica.
\end{abstract}

Palabras clave: Hiperplasia paratiroidea ectópica, hemitiroidectomía, gammagrafía de paratiroides Mibi Tc-99m.

Abstract

The case of a patient who satisfactorily underwent left hemithyroidectomy for nodular goiter is reported. Pathology study of the specimen stated enlarged left thyroid gland lobe due to hyperplasic intrathyroidal parathyroid. With this result parathyroid gammagraphy was obtained and a right thoracic capture area was reported. Final diagnosis was ectopic parathyroid hyperplasia of double localization, intrathoracic and intrathyroidal.

Keywords: Ectopic parathyroid hyperplasia, hemithyroidectomy, Mibi Tc-99m parathyroid gammagraphy.

An Fac med. 2013;74(4):335-8

\section{INTRODUCCIÓN}

En la mayoría de los seres humanos existen cuatro glándulas paratiroides. Se conoce la existencia de glándulas paratiroides ectópicas en ubicaciones inusuales, como el timo, mediastino, intratiroideo, posición no descendida, dentro de la vaina carotídea y raramente en la submucosa del esófago e hipofaringe ${ }^{(1)}$. Embriológicamente las paratiroides inferiores se originan de la tercera bolsa faríngea, mientras que las superiores, de la cuarta bolsa faríngea. Las anomalías en el número y posición anatómica de las glándulas paratiroides son comunes, lo que constituye un desafío para el cirujano en el manejo de pacientes con hiperparatiroidismo, especialmente en los casos de persistencia o recurrencia de la enfermedad después de la paratiroidectomía.

El 80\% de los casos de hiperparatiroidismo primario se debe a la presencia de un adenoma de la glándula paratiroides; en menor proporción deviene de hiperplasia (asociada o no a neoplasia endocrina múltiple) o cáncer de la glándula, por lo que una vez hecho el diagnóstico bioquímico de la enfermedad se debe intentar identificar la causa u origen. El hiperparatiroidismo primario es causa frecuente de aumento del calcio sérico. El diagnóstico se realiza habitualmente en forma accidental, al informarse una hipercalcemia en un examen bioquímico de rutina. La hipercalcemia puede originar urolitiasis a repetición, artritis cálcica, pancreatitis recurrente, enfermedad péptica de difícil tratamiento, trastornos de personalidad en ancianos, entre otros. Se confirma el diagnóstico midiendo, además de la calcemia, la fosfemia (disminuida) y la paratohormona intacta, que está elevada; la utilización de la cintigrafía con tecnecio y MIBI aumenta la sensibilidad y especificidad en el diagnóstico ${ }^{(2)}$.
En los casos de hiperparatiroidismo secundario, todas las glándulas paratiroides, incluyendo las supernumerarias, casi siempre son hiperplásicas, pudiendo constituir un problema clínico significativo ${ }^{(1)}$.

Una vez detectada la hiperplasia o el adenoma, se plantea la indicación quirúrgica, pudiéndose realizar cervicotomía exploradora o cirugía radioguiada mínimamente invasiva, resecando la glándula alterada; se espera una rápida normalización de los niveles de calcio sérico ${ }^{(2)}$. En el caso de hiperplasia de las glándulas paratiroides, el tratamiento consiste en la extirpación de las glándulas comprometidas, pudiendo llegar a la extirpación de tres y medio de ellas y si es necesario se recurre a la implantación de la mitad restante en el músculo esternocleidomastoideo, controlando posteriormente el descenso en los niveles de paratohormona y de calcemia. 


\section{CASO CLÍNICO}

Se presenta el caso de una paciente de 62 años de edad, soltera, ama de casa y con instrucción técnica, natural de Tumbes, procedente del distrito de La Victoria (Lima), y tiempo de enfermedad de aproximadamente un año, de inicio insidioso y curso progresivo. Acudió al consultorio de Cirugía de Cabeza, Cuello y Máxilo-Facial por presentar aumento de tamaño de $+/-3 \mathrm{~cm}$ de diámetro en la región cervical anterior izquierda supraesternoclavicular, que correspondía a la ubicación de la glándula tiroides. Era firme y de consistencia media, indolora, móvil a la deglución, de característica nodular y circunscrita, de bordes bien definidos; no había congestión en la piel adyacente. Dentro de los antecedentes de importancia, la paciente no manifestaba alergias a medicamentos ni de otro tipo, era portadora de diabetes mellitus desde hacía 13 años y en tratamiento, hipertensión arterial desde hacía 3 años y en tratamiento, cesareada una vez en el año 1986 e histerectomizada en el año 1992, sin precisar la causa. Se planteó la impresión diagnóstica de bocio nodular izquierdo.

La paciente portaba de otra institución ecografía de partes blandas del cuello con resultado de nódulo tiroideo izquierdo, gammagrafía de tiroides con I ${ }^{131}$ compatible con nódulo frío en lóbulo izquierdo y biopsia por aspiración con aguja fina negativo para células neoplásicas. Se le solicitó nueva ecografía de tiroides con resultado de bocio nodular izquierdo. La biopsia por aspiración con aguja fina fue compatible con bocio nodular tiroideo, sin atipia. El perfil tiroideo ( $\mathrm{TSH}, \mathrm{T}_{3}$ y $\mathrm{T}_{4}$ ) estuvo dentro de rangos normales. Se planteó realizar hemitiroidectomía izquierda (lobectomía izquierda + istmectomía). Los exámenes preoperatorios estuvieron dentro de los rangos normales, excepto descenso de la creatinina en sangre a $0,4 \mathrm{mg} / \mathrm{dL}$ (valor normal en mujeres: 0,7 a $1,2 \mathrm{mg} / \mathrm{dL}$ ) y el examen de orina con más de 100 leucocitos por campo y filamentos mucoides; en Urología le solicitaron ecografía renal y vesical, don-

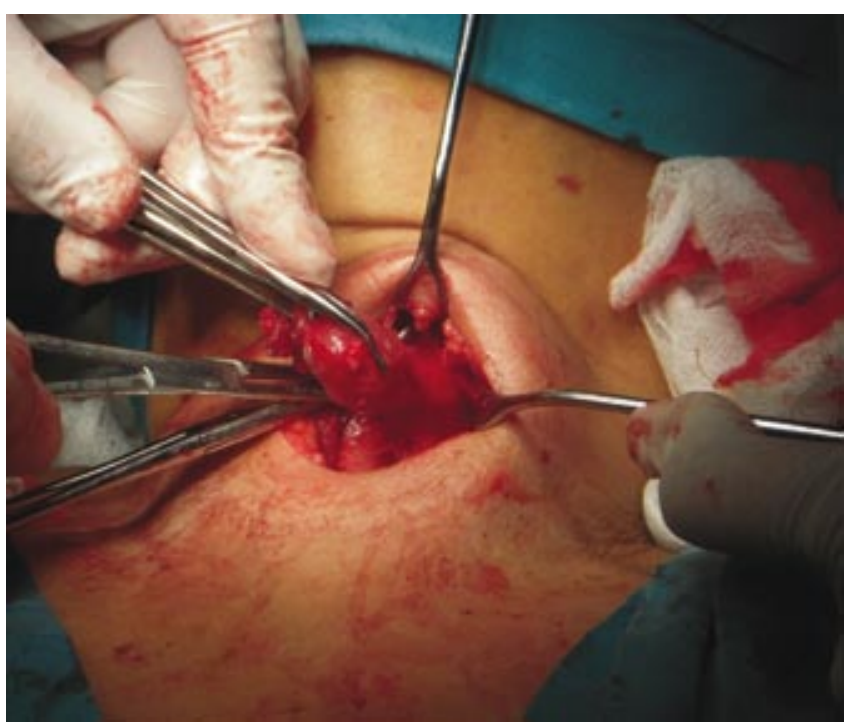

Figura 1. Procedimiento quirúrgico de hemitiroidectomía izquierda.

de se halló imagen quística de $15 \mathrm{~mm}$ de diámetro en polo inferior del riñón derecho y algunas imágenes microlitiásicas menores de $2 \mathrm{~mm}$ de diámetro en ambos riñones (arenilla renal bilateral); el urocultivo fue positivo a E. coli, recibiendo tratamiento. La paciente también fue evaluada por Endocrinología.

Se realizó la hemitiroidectomía izquierda sin complicaciones (figuras 1 y 2). En el acto operatorio se visualizó el nervio recurrente o laríngeo inferior del lado izquierdo sin alteraciones; la glándula paratiroides correspondiente al polo superior del lóbulo tiroideo izquierdo no evidenció alteraciones aparentes en su morfología (figura 3). No se visualizó la glándula paratiroides correspondiente al polo inferior del lóbulo tiroideo izquierdo ni se evidenció otras alteraciones o tumoraciones en la zona operatoria. La paciente evolucionó favorablemente, con voz clara y de buena intensidad; no presentó hipocalcemia; salió de alta y continuó controles por consultorio externo de la especialidad.

Durante sus controles por consultorio externo se recibió el informe anátomo-patológico de la pieza operatoria, que concluyó como glándula paratiroides hiperplásica en lóbulo tiroideo (figura 4). Con este resultado se solicitó a la paciente dosaje de calcio sérico $(9,5$ $\mathrm{mg} / \mathrm{dL}$; valor normal 8,5 a $10,5 \mathrm{mg} /$ dL) y de hormona paratiroidea $(64,55$ $\mathrm{pg} / \mathrm{mL}$; valor normal 15 a $65 \mathrm{pg} / \mathrm{mL})$, la hormona paratiroidea estaba en su límite superior. La gammagrafía de paratiroides Mibi Tc-99m mostró área de captación en la región torácica derecha que podría estar en relación a adenoma ectópico de paratiroides (figura 5); la radiografía de tórax preoperatoria fue

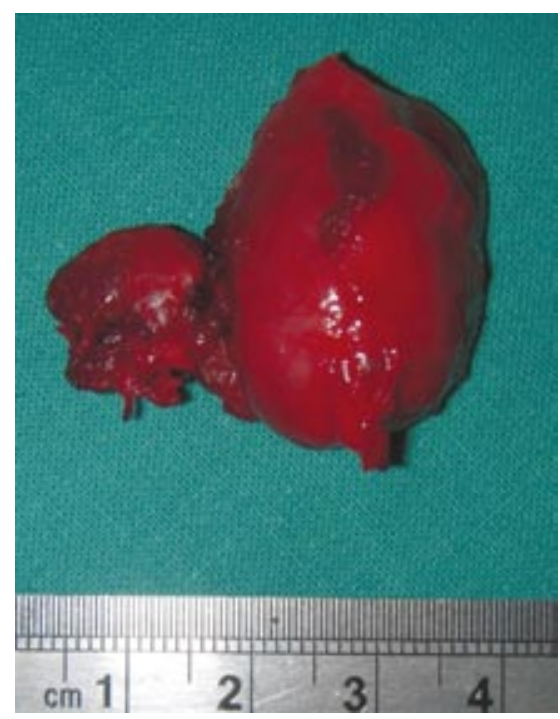

Figura 2. Pieza operatoria de hemitiroidectomía izquierda, lóbulo tiroideo izquierdo (incluido el nódulo palpable) e istmo. 


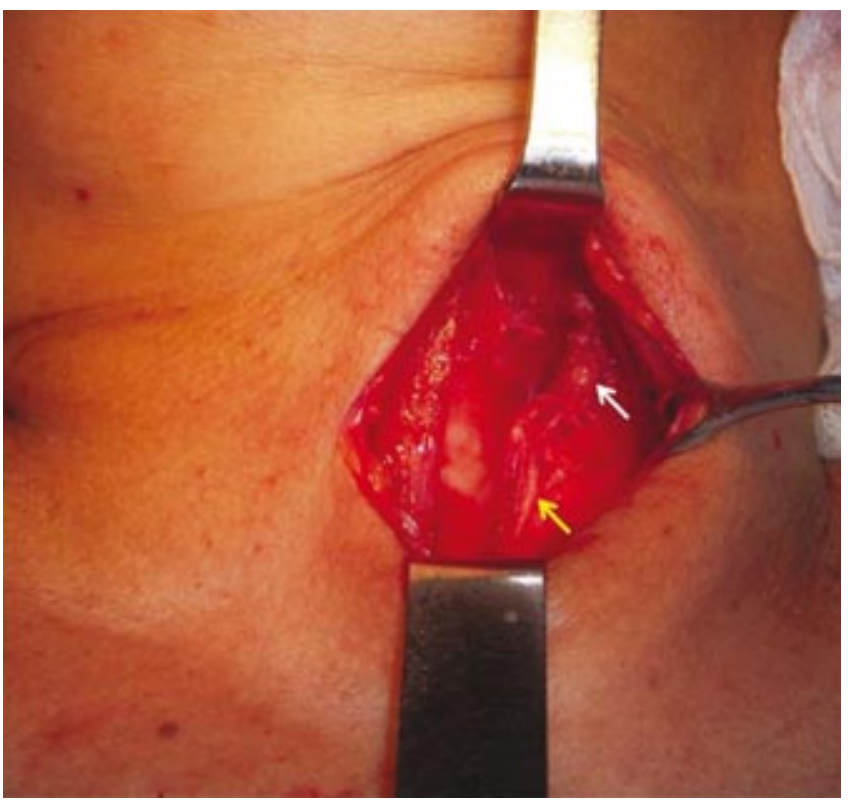

Figura 3. Lecho operatorio luego de la hemitiroidectomía izquierda; se identifica y conserva el nervio recurrente (flecha amarilla) y la glándula paratiroides superior (flecha blanca).

normal. La paciente fue enviada a los servicios de Endocrinología y Cirugía de Tórax para su evaluación respectiva, pero no regresó.

\section{DISCUSIÓN}

Se presenta el caso de una paciente que ingresó con diagnóstico presuntivo de bocio nodular izquierdo, pero que después de hemitiroidectomía izquierda y del estudio anátomo-patológico se planteó el diagnóstico de hiperplasia paratiroidea intratiroidea. Cabe resaltar que durante el acto operatorio no se logró identificar a la glándula paratiroides inferior izquierda. Con el resultado del estudio anátomo-patológico se procedió a realizar otros estudios orientados al funcionamiento de la glándula paratiroides, especialmente la gammagrafía Mibi Tc-99m, con los que se llegó al diagnóstico definitivo de hiperplasia paratiroidea ectópica de doble localización, intratiroidea e intratorácica.

Son conocidas las anomalías en número y ubicación de las glándulas paratiroides. Lo que no es común es la coincidencia de que a la alteración en la ubicación glandular se agregue la hiperplasia glandular y aún más que sean distintas las dos ubicaciones.

La primera inquietud que se tuvo $-y$ se le comunicó al patólogo- fue que se

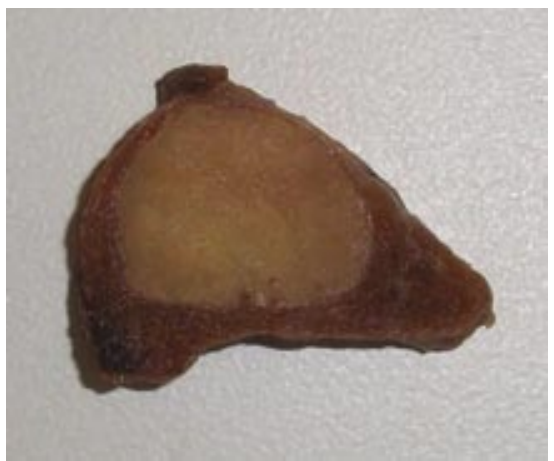

Figura 4. Pieza operatoria de hemitiroidectomía izquierda, sección del lóbulo tiroideo izquierdo en su parte media. Véase la glándula paratiroides crecida en su interior, correspondiente al nódulo palpable clínicamente (foto cortesía del Dr. Alejandro Alfaro Lozano, médico patólogo del Hospital Nacional Dos de Mayo)

trataba de un adenoma de paratiroides y no de una hiperplasia, por el hallazgo único y la evidencia intraoperatoria de una glándula paratiroides de características normales (a nivel del polo superior del lóbulo tiroideo izquierdo). La lámina fue nuevamente revisada por el patólogo, siendo concluyente en que se trataba de una 'glándula paratiroides hiperplásica en lóbulo tiroideo'.

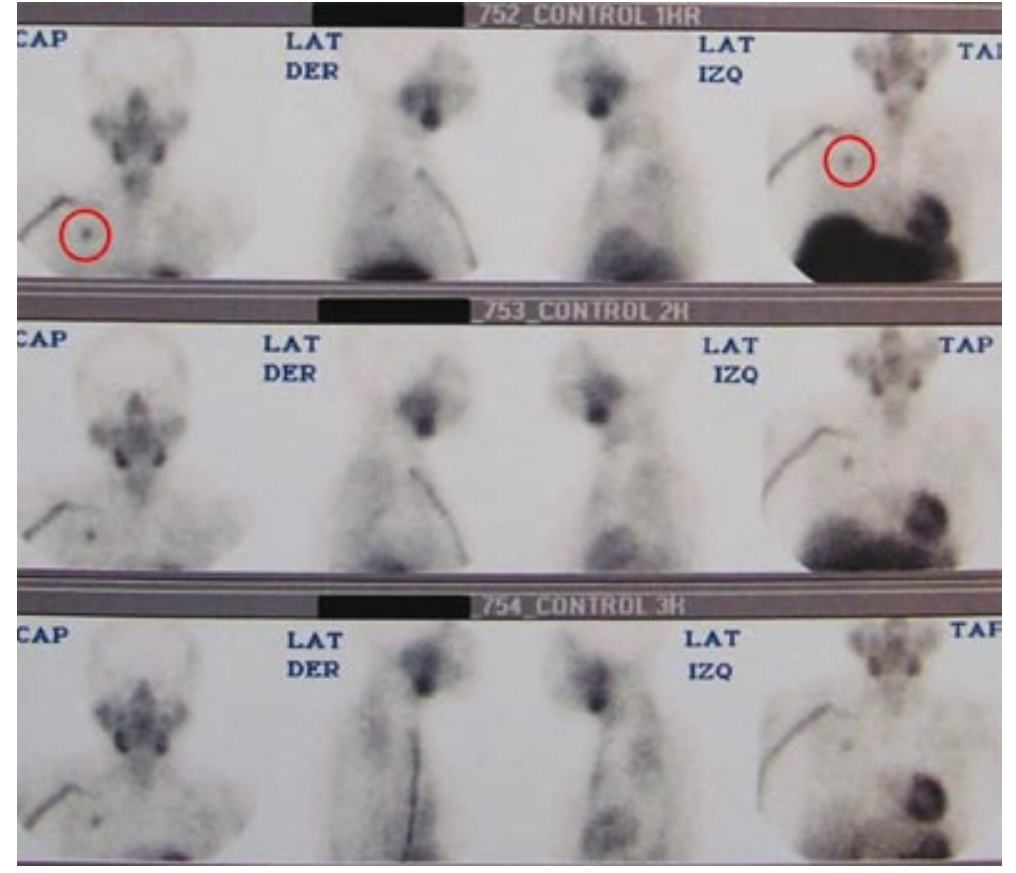

Figura 5. Gammagrafía de paratiroides Mibi Tc-99m, en la que se muestra área de captación en la región torácica derecha (círculo rojo). 
La hiperplasia de paratiroides es más frecuente encontrarla en las cuatro glándulas; pero puede presentarse en menos, sin que esto sea lo habitual. Lo mismo, el adenoma de paratiroides es muy raro que se presente en dos glándulas.

Las glándulas paratiroides inferiores se originan embriológicamente de la tercera bolsa faríngea, aproximadamente durante la quinta semana de desarrollo; se originan a este nivel junto con el timo. Cuando las paratiroides inferiores y el timo pierden contacto con la pared faríngea, comienzan a ubicarse en su posición definitiva. El timo desciende hacia la región intratorácica retroesternal y es en ese momento que puede arrastrar consigo alguna paratiroides inferior, pudiendo haber sido el caso de la paciente en mención.

En la gammagrafía de paratiroides Mibi Tc-99m se informó un área de captación en tórax derecho compatible con adenoma ectópico de paratiroides, como foco único, esto debido a que ya no existía el foco cervical intratiroideo, ya operado, con diagnóstico anátomopatológico de hiperplasia paratiroidea. Si se hubiera tenido el dato de la gammagrafía de paratiroides previo a la cirugía, se hubiera visto dos imágenes anómalas de captación, en cuello y tórax respectivamente, compatibles a la imagen gammagráfíca con hiperplasia de paratiroides; sin embargo, el examen clínico y los exámenes auxiliares orientaron la patología hacia la glándula tiroides. De igual manera la paciente no tenía sintomatología de patología paratiroidea.

Cuando se presentó el caso -hace aproximadamente dos años-, no se tenía la disponibilidad de la tomografía computarizada por emisión de fotón simple (SPECT), gran complemento en el estudio de casos similares. Se solicitó la gammagrafía de paratiroides Mibi Tc99m, que cumplió en forma adecuada para los fines que se necesitaba, que era la ubicación y la captación de tejido paratiroideo.

Es importante el conocimiento del presente caso clínico, además de cirugía de cabeza y cuello, en varias especialidades, por las repercusiones que puede tener en el organismo la hiperplasia paratiroidea, el adenoma paratiroideo y el hiperparatiroidismo.

En la bibliografía consultada se encontró casos de hiperplasia y de adenomas ectópicos, pero ninguno como el que se está presentando. Se le comunicó a la paciente en repetidas oportunidades la necesidad de seguir sus controles, especial y principalmente por Endocrinología, pero no los continuó ni volvió al servicio de Cabeza y Cuello para continuar su control postoperatorio.

\section{REFERENCIAS BIBLIOGRÁFICAS}

1. Hung CJ, Lin PW, Lee PC, Chen HH, Chen FF. Caso clínico: Supernumerary intravagal parathyroid hiperplasia. Surgery. 2002;131(3):359-61.

2. León RA. Patología Quirúrgica de las Glándulas Paratiroides. Manual de Patologia Quirúrgica de Cabeza y Cuello. Pontificia Universidad Católica de Chile. Disponible en: http://escuela.med.puc.cl/ publ/manualcabezacuello/Indice.html.

3. Orrego MA. Endocrinología 2.a edición. Editorial Universidad de Antioquia, Medellin-Colombia 2009.

4. Arce VM, Catalina PF, Mallo F. Endocrinologia. Universidad de Santiago de Compostela, Universidad de Vigo, España, 2006.

5. Pando RM. Hiperparatiroidismo. Rev Diagnóstico, Lima-Perú. 2011;50(1).

6. Szabo E, Lundgren E, Juhlin C, Ljunghall S, Akerstrom G, Rastad J. Double parathyroid adenoma, a clinically nondistinct entity of primary hyperparathyroidism. World J Surg. 1998;22:708-13.

7. Sitges-Serra A, Sancho JJ, Pereira JA, Girvent M, Pascual M, Berná L. Hiperparatiroidismos debidos a glándulas paratiroides de localización torácica. Cir Esp. 2003;73:213-7.

8. Barriga-Sánchez R, Larrañaga E, García JL, Tamura A, Pun Y, Martín E. Nueva técnica quirúrgica para glándulas paratiroides intratorácicas: la videotoracoscopia con detección de Tc-MIB intraoperatoria. Cir Esp. 2006;79:255-7.

9. Prats E, Razola P, Tardin L, Andrés A, Garcia López F, Abós MD, Banzo J. Gammagrafia de paratiroides y cirugía radiodirigida en el hiperparatiroidismo primario. Rev Esp Med Nucl. 2007;26(5):310-28.

10. Betancourt A, Bonnet I, Arias C, López D, Contreras E. Hiperparatiroidismo primario: adenoma o hiperplasia. Rev cienc biomed. 2012;3(2):350-4.

11. Goñi I, Campusano C, Gejman R, Orellana P. Hiperparatiroidismo primario de origen multiglandular con glándula paratiroides intratiroidea hiperfuncionante. Rev Chil Cir. 2011;63(4):418-21.

Artículo recibido el 13 de febrero de 2013 y aceptado para publicación el 24 de julio de 2013.

Caso clínico presentado con seudónimo al concurso de trabajos de investigación del Hospital Nacional Dos de Mayo, febrero 2013, y remitido para publicación a la Revista Anales.

Correspondencia:

Dr. Francisco Avello Canisto

Correo electrónico: favelloc@hotmail.com 